EDITORIAL

\title{
Variantes del SARS-Cov-2
}

[Variants of SARS-Cov-2]

DOI: 10.37980/im.journal. rspp.20211846
Desde la aparición de los primeros casos o clusters de cuadros de neumonia de Covid 19 en Wuhan, en la provincia de Hubei en China a finales de noviembre-diciembre del 2019, el SARS-Cov-2 ha representado un reto para la comunidad científica, primero encontrar el agente etiológico y posterior la aparición de las nuevas variantes, denominación dada a la evolución del virus original o salvaje debido a cambios en el código genético (mutación genética) que ocurren durante la replicación del genoma en este caso del SARS-Cov-2.

Estas nuevas mutaciones pueden variar del original en mayor velocidad de transmisión, mayor virulencia, que interfieran en la protección del individuo vacunado antes las nuevas variantes, inmunidad del individuo que ha padecido la infección, menor efectividad de los tratamientos, fallas en los métodos diagnósticos.

Según el CDC, por la continua evolución del SARS-CoV-2 y del impacto de las variantes sobre la salud pública, las variantes las han reclasificado con base en sus atributos y prevalencia. ${ }^{1,2}$

- Variantes bajo monitoreo (VBM, por sus siglas en inglés)- Vea las VBM actuales en los Estados Unidos que las agencias federales continúan monitoreando y caracterizando. Las variantes designadas como VBM incluyen aquellas cuyos datos indican que existen un impacto claro o potencial sobre las contramedidas médicas aprobadas o autorizadas o que se han asociado a casos de enfermedad más graves o a una mayor transmisión pero que ya no se detectan, o están circulando a niveles muy bajos. Como son: Alfa, Beta, Gamma, Mu, Epsilon, Eta, lota, Kappa, N/A, Zeta, Lambda, Theta.

- Variante de interés (VOI)- Actualmente, ninguna de las variantes del SARS-CoV-2 tiene la designación de VOI. Variante con marcadores genéticos específicos a los que se ha asociado a cambios en la unión al receptor, una menor neutralización por los anticuerpos generados contra una infección anterior o la vacunación, una menor eficacia de los tratamientos, el posible impacto del diagnóstico, o el aumento pronosticado en la transmisibilidad o gravedad de la enfermedad, que sea responsable de aumento de casos o de brotes de clusters específicos.

- $\quad$ Variante de preocupación (VOC, por sus siglas en inglés)- Vea las VOC que las agencias federales de los Estados Unidos están monitoreando de cerca y caracterizando. Variante para la cual hay evidencia de una mayor transmisibilidad, con casos más graves de enfermedad (mayor cantidad de hospitalizaciones o muertes), reducción significativa en la neutralización por los anticuerpos generados durante una infección anterior o la vacunación, menor efectividad de los tratamientos o las vacunas, o fallas de detección de diagnóstico.

En estos momentos las dos variantes de preocupación son:

- La variante delta (también conocida como variante india o P.1). Los linajes AY.1 y AY.2 no son susceptibles a algunos de los tratamientos con anticuerpos monoclonales. En 184 países es la cepa predominante en estos momentos de los casos reportados hasta diciembre 2021, en Latinoamérica representan del 90 al $99 \%$ de los casos $^{3}$, como observamos en el gráfico 1 obtenido de GISAID (Global Data Science Initiative) ${ }^{4}$.

- La variante omicrón (variante sudafricana o linajes B.1.1.529 y BA) esta variante es la última notificada el 24 de noviembre del 2021 desde Sudafrica. Hasta el 18 de diciembre del 2021, 70 países han reportado casos de la variante omicrón. 
Gráfica 1. Porcentaje de infecciones por cepas de Covid 19 en Latinoamérica.

\section{Las cepas de COVID-19 más comunes en Latinoamérica}

Porcentaje de nuevas infecciones de COVID-19

en las últimas 4 semanas, por variante

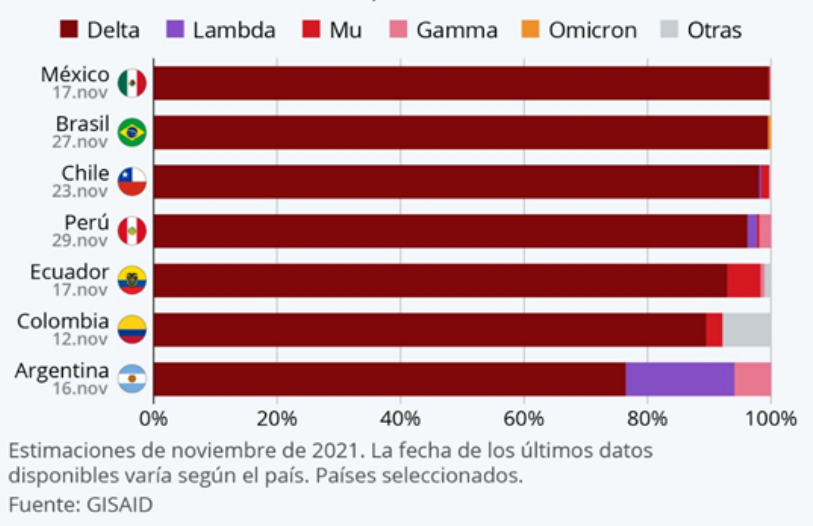

(두) (i) $\odot$

statista

- Variante de gran consecuencia (VOHC)-Actualmente, ninguna de las variantes del SARS-CoV-2 tiene la designación de VOHC. La variante VOHC muestra una clara evidencia de que las medidas de prevención o las medidas médicas paliativas (MCM, por sus siglas en inglés) han reducido significativamente la efectividad con respecto a las variantes que circularon previamente, se presenta una alta tasa de infección en vacunados y disminuye la protección contra las formas graves.

Este virus seguirá su evolución a través de las mutaciones genéticas y podrá quizás quedar como un virus estacional como la influenza donde tendremos que aplicarnos anualmente la vacuna o probablemente desaparecerá. Mientras tanto debemos seguir con las medidas de prevención y distanciamiento social, además de la aplicación de las vacunas y refuerzo para disminuir la incidencia de las formas graves de esta infección.

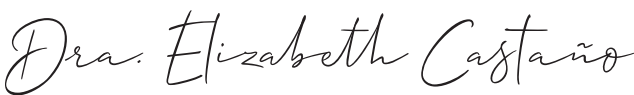

\section{Dra. Elizabeth Castaño Editora Jefe}

\section{Referencias}

1. CDC. Science Brief: Emerging SARS-CoV-2 Variants. National Center for Immunization and Respiratory Diseases (NCIRD), Division of Viral Diseases . December 13, 2021.

2. Cascella M, Rajnik M, Aleem A et al. Features, Evaluation, and Treatment of Coronavirus (COVID-19) [Updated 2021 Sep 2]. In: StatPearls [Internet]. Treasure Island (FL): StatPearls Publishing; 2021 Jan-. Available from: https://www.ncbi.nlm.nih.gov/books/NBK554776/

3. Pasqualini M. Las variantes de COVID-19 más extendidas en América Latina. https://es.statista. com/grafico/25274/variantes-de-covid-19-en-latinoamerica/ Diciembre, 2021.

4. Khare, S., et al (2021) GISAID's Role in Pandemic Response. China CDC Weekly, 3(49): 1049-1051. doi: $10.46234 / c c d c w 2021.255$ 